\title{
CORRIGENDUM
}

\section{Climate change and the recent emergence of bluetongue in Europe}

Bethan V. Purse, Phillip S. Mellor, David J. Rogers, Alan R. Samuel, Peter P.C. Mertens and Matthew Baylis Nature Reviews Microbiology 3, 171-181 (2005)

On page 172 of the above article, we wrote that: “In subsequent years up to 2004, BTV-9 spread northward (into western regions of Turkey, Bulgaria, Kosovo, Albania, Bosnia and Herzegovina, the former Yugoslav republic of Macedonia, Serbia and Montenegro, and Croatia) and westward (into mainland Greece, Italy, Sicily, Sardinia and Corsica)." In fact, BTV-9 has not been recorded in Sardinia and Corsica. Only three serotypes BTV-2, BTV-4 and BTV-16 have been detected on each of these islands. The authors apologize for this error. 